\title{
Badania strukturalne i wytrzymałościowe stopu Co-Cr-Mo na konstrukcje protetyczne w technologii odlewania i spiekania laserowego
}

\begin{abstract}
Streszczenie. Laserowe spiekanie proszków metali (DMLS) jest nową technologią otrzymywania konstrukcji w procedurze CAD/CAM. Celem była identyfikacja strukturalna i wyznaczenie parametrów wytrzymałościowych stopu kobaltu na stałe uzupełnienia protetyczne wykonywane w dwóch technologiach. Materiałem badań był stop Co-Cr-Mo, z którego uzyskano próbki w technologii odlewania oraz w technologii DMLS. Stwierdzono, że DMLS jest technologią preferowaną do wykonawstwa konstrukcji dla protetyki i może stanowić alternatywę dla tradycyjnej metody odlewania.

Abstract. Direct Metal Laser Sintering (DMLS) is a new technology for obtaining reconstruction in the CAD / CAM procedure. The aim was to identify the structural and determination of strength parameters of cobalt alloy intended for fixed prosthetic restorations. carried out in two technologies. Test material was a Co-Cr-Mo alloy, from which the sample were obtained in a casting technology and DMLS technology. It was found that the DMLS is preferred technology for manufacturing reconstruction for prosthetics and can be an alternative to the traditional method of casting. (Microstructural and strength studies Co-Cr-Mo alloy on prosthetic reconstructions in casting technology and laser sintering).
\end{abstract}

Słowa kluczowe: Co-Cr-Mo, protetyka stomatologiczna, mikrostruktura, twardość.

Keywords: Co-Cr-Mo, dental prosthetics, microstructure, hardness.

\section{Wprowadzenie}

Obecnie najczęściej stosowaną metodą otrzymywania metalowych konstrukcji protetycznych jest odlewanie precyzyjne, które odbywa się metodą traconego wosku. W tej technologii korony i mosty o indywidualnych kształtach otrzymuje się na podstawie modeli woskowych, które kształtuje się na modelu roboczym łuku zębowego pacjenta. W kolejnych procesach następuje wypalanie wosku i zastąpienie go płynnym metalem w odlewaniu odśrodkowym lub próżniowo-ciśnieniowym. W ostatnich latach $\mathrm{w}$ wykonawstwie stałych uzupełnień protetycznych coraz szersze zastosowanie znajduje technologia Selective Laser Sintering (SLS) w tym Direct Metal Laser Sintering (DMLS) [1-7]. Została ona opracowana przez niemiecka firmę Electro Optical Systems $\mathrm{GmbH}$ (EOS). Z wykorzystaniem tej technologii można zrealizować wykonanie konstrukcji terapeutycznej w CAD/CAM. Na etapie CAM podbudowa metalowa jest wytwarzana poprzez spiekanie wiązka lasera proszków metali w kolejnych warstwach. W urządzeniu dedykowanym pracom stomatologicznym na platformę roboczą nanoszona jest warstwa proszku o grubości $0,02 \mathrm{~mm}$, a następnie wiązka lasera światłowodowego $\mathrm{Yb}$ (Ytterbium-Fibre-Laser) $\mathrm{O}$ nominalnej mocy 200W z zakresu podczerwieni jest prowadzona po powierzchni proszku zgodnie z bitmapą będącą wirtualnym zapisem tworzonej podbudowy. Następnie platforma robocza obniża się i nanoszona jest kolejna warstwa proszku. Szybkie utwardzanie po stopieniu prowadzi do powstania homogennej struktury materiału. Po zakończeniu procesu spiekania nadmiary niewykorzystanego proszku mogą zostać użyte w kolejnym cyklu produkcyjnym. Obniża to koszty produkcji i minimalizuje proces recyklingu odpadów. W technologii DMLS można wytwarzać podbudowy o dowolnej długości od pojedynczych koron, aż do rozległych mostów.

Celem opracowania była identyfikacja strukturalna i wyznaczenie parametrów wytrzymałościowych stopu CoCr-Mo, z którego wykonywane są podbudowy stałych konstrukcji protetycznych:

- w tradycyjnej technologii precyzyjnego odlewania metodą próżniowo-ciśnieniową,
- $\mathrm{w}$ technologii laserowego przyrostowego spiekania z selektywnych proszków metali.

\section{Materiał i metody}

Do grupy badawczej zaliczono próbki wykonane ze stopu CoCr typ 5 DIN EN ISO 22674 o nazwie Remanium GM 800+ (Dentaurum, Ispringen, Germany) wykonane technologią odlewania próżniowo-ciśnieniowego oraz próbki ze stopu kobaltu o nazwie EOS CobaltChrome SP2 (Electro Optical System GmbH, München, Germany) - SP2 wykonane technologią DMLS w urządzeniu EOSINT M 270 dedykowanym konstrukcjom stomatologicznym (Tab.1). Z obu materiałów w przewidzianych dla nich procedurach technologicznych wykonano po 10 prostopadłościennych próbek o wymiarach $15 \mathrm{~mm} \times 5 \mathrm{~mm} \times 2 \mathrm{~mm}$.

Tabela 1. Kompozycja materiałowa

\begin{tabular}{|c|c|c|}
\hline \multirow{2}{*}{ Pierwiastek } & \multicolumn{2}{|c|}{ Koncentracja, wt-\% } \\
\cline { 2 - 3 } & $\begin{array}{c}\text { Remanium GM } \\
800+\end{array}$ & EOS CobaltChrome SP2 \\
\hline Kobalt & 63.3 & $61.8-65.8$ \\
\hline Chrom & 30 & $23.7-25.7$ \\
\hline Molibden & 5 & $4.6-5.6$ \\
\hline Wolfram & $<1$ & $4.9-5.9$ \\
\hline Krzem & 1 & $0.8-1.2$ \\
\hline Żelazo & - & max. 0.50 \\
\hline Mangan & $<1$ & max. 0.10 \\
\hline Weggiel & $<1$ & - \\
\hline Azot & $<1$ & - \\
\hline
\end{tabular}

Analizy strukturalne i wytrzymałościowe przeprowadzono na wyszlifowanych, wypolerowanych $\mathrm{i}$ wytrawionych zgładach. W tym celu próbki inkludowano w żywicy i polerowano pastami polerskimi, aż do osiągnięcia warstwy wierzchniej wymaganej do badań mikrostrukturalnych. Kolejnym etapem było trawienie próbek w wodzie królewskiej o składzie: 3 części kwasu solnego $\mathrm{HCl}$ i 1 części kwasu azotowego $\mathrm{HNO}_{3}$.

Badania mikrostrukturalne próbek odlewanych z Remanium GM 800+ i próbek spiekanych EOS CobaltChrome SP2 zrealizowano z wykorzystaniem mikroskopu skaningowego firmy JOEL JSM 5510LV z 
przystawką do analizy energii promieniowania rentgenowskiego IXRF System 500 Digital Processing. Przystawka umożliwiła jakościowe i ilościowe określenie składu chemicznego w postaci rozkładu punktowego.

Pomiary twardości metodą Vickersa przeprowadzono z wykorzystaniem urządzenia Instron Wolpert TESTOR 2100. Badanie polegało na wciśnięciu diamentowego wgłębnika w badaną próbkę z obciążeniem $1,961 \mathrm{~N}$, przy określone prędkości obciążania i odciążania. Na podstawie pomiarów przekątnych odcisków wyznaczono twardość Vickersa. Badanie przeprowadzono według znormalizowanej procedury [8]. Twardość Vickersa wyznaczono na podstawie 25 pomiarów wykonanych na każdej próbce. $\mathrm{Na}$ opracowanych powierzchniach automatycznie nanoszono siatkę punktów, w których dokonywano wgłębnikowania (rys.1).

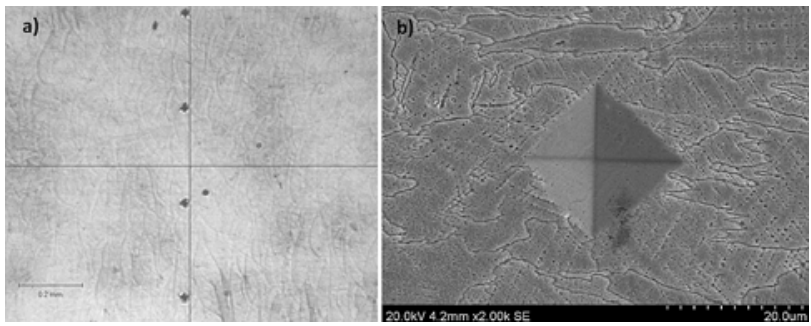

Rys.1. Metodyka wykonywania pomiarów twardości na próbce SP2: a) rozmieszczenie punktów pomiarowych, b) obraz SEM odcisku penetratora

\section{Wyniki badań}

Badania mikroskopowe

Badania mikroskopowe przeprowadzono na 20 próbkach. W wynikach zamieszczono przykładowe obrazy SEM i analizy w punktach.
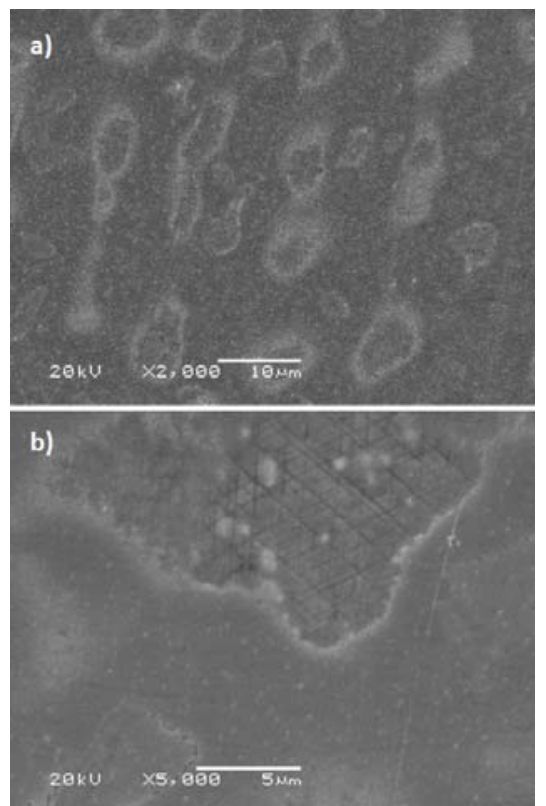

Rys.2. Obrazy SEM mikrostruktury stopu Co-Cr-Mo z technologii odlewania próżniowo-ciśnieniowego

Wyniki badań skaningowych stopu Remanium GM 800+ oraz stopu EOS CobaltChrome SP2 obejmowały obrazy SEM wykonane $z$ wykorzystaniem mikroskopu JOEL JSM 5510LV, a także analizy składu chemicznego w wybranych losowo punktach mikroobszarów, z wykorzystaniem przystawki EDS. Sekwencja rysunków 2 i 3 przedstawia wybrane reprezentatywne obrazy SEM mikrostruktury próbek stopu Co-Cr-Mo wykonane w obu technologiach. W próbce ze stopu Co-Cr-Mo z technologii odlewania próżniowo-ciśnieniowego widoczne są układy dendrytyczne (rys.2).
W strukturze spiekanego stopu SP2 widoczne sa zarysowania granic ziaren. Występują obszary ziaren równoosiowych jak i ziaren o silnie wydłużonym kształcie, co zapewnia jej dużą zwartość (rys.3). Równocześnie we wszystkich analizach nie stwierdzono występowania porowatości, które mogłyby obniżać wytrzymałość konstrukcji nośnej. Wykorzystując przystawkę EDS dokonano analizy składu chemicznego dla obu badanych biomateriałów. W mikroobszarze powierzchni Remanium GM 800+ rozpoznano obecność kobaltu, chromu, molibdenu i wolframu. Badaniu poddano po dwa wybrane losowo punkty na 20 powierzchniach (rys.4). Składy chemiczne poszczególnych punktów przedstawiono w tabeli 2. W badanych punktach występują nieznaczne różnice w składzie chemicznym.
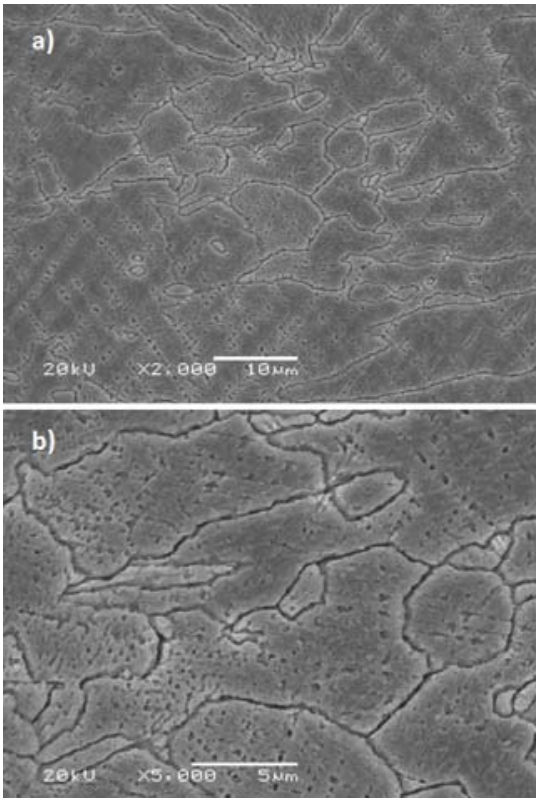

Rys.3. Obrazy SEM mikrostruktury stopu Co-Cr-Mo z technologii DMLS

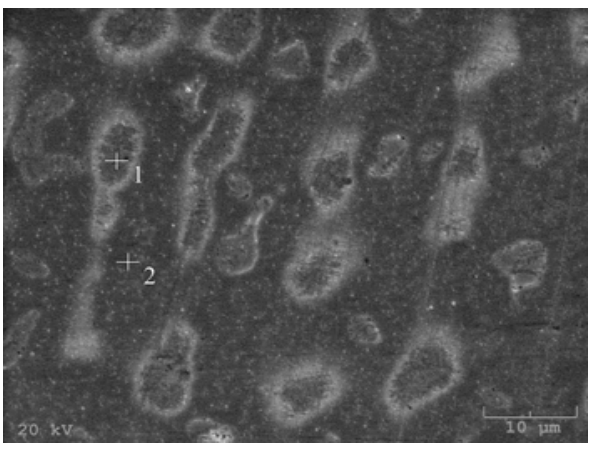

Rys.4. Obrazy SEM mikrostruktury stopu Co-Cr-Mo z technologii odlewania próżniowo-ciśnieniowego z zaznaczonymi punktami do analizy składu chemicznego

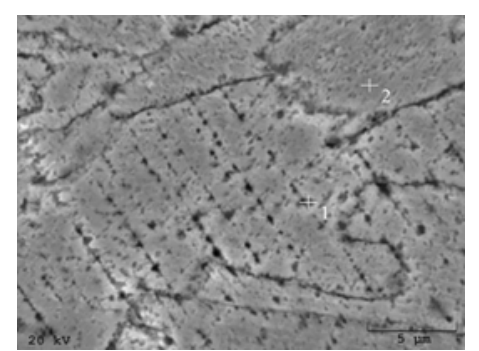

Rys.5. Obrazy SEM mikrostruktury stopu Co-Cr-Mo z technologii DMLS z zaznaczonymi punktami do analizy składu chemicznego 
Podobna analize przeprowadzono dla stopu SP2 ze spiekania. Na badanej powierzchni zidentyfikowano kobalt, chrom, molibden i wolfram. Analizie poddano również po dwa punkty na badanej powierzchni (rys.5). Składy chemiczne poszczególnych punktów przedstawiono w tabeli 3

Tabela 2. Skład chemiczny w wybranych punktach na powierzchni w próbce ze stopu Co-Cr-Mo z technologii odlewania próżniowociśnieniowego

\begin{tabular}{|c|c|c|c|c|c|}
\hline & Pierwiastek & \begin{tabular}{|c} 
Intensywność \\
(c/s)
\end{tabular} & \begin{tabular}{|l|} 
Błąd \\
2-sig
\end{tabular} & \begin{tabular}{|c|} 
Udział atomowy \\
$(\%)$
\end{tabular} & $\begin{array}{c}\text { Koncentracja } \\
\text { (wt.\%) }\end{array}$ \\
\hline & $\mathrm{Co}$ & 198,41 & 2,467 & 58,182 & 57,816 \\
\hline & $\mathrm{Cr}$ & 176,36 & 2,365 & 36,718 & 32,192 \\
\hline 1 & Mo & 20,37 & 0,809 & 3,925 & 6,349 \\
\hline & W & 3,08 & 0,329 & 1,175 & 3,643 \\
\hline & & & & 100,000 & 100,000 \\
\hline \multirow{5}{*}{2} & Co & 183,63 & 2,403 & 54,717 & 54,208 \\
\hline & $\mathrm{Cr}$ & 184,13 & 2,419 & 39,120 & 34,195 \\
\hline & Mo & 26,11 & 0,920 & 5,041 & 8,131 \\
\hline & W & 2,91 & 0,324 & 1,122 & 3,467 \\
\hline & & & & 100,000 & 100,000 \\
\hline
\end{tabular}

Tabela 3. Skład chemiczny w wybranych punktach na powierzchni w próbce ze stopu Co-Cr-Mo z technologii DMLS

\begin{tabular}{|c|c|c|c|c|c|}
\hline & Pierwiastek & $\begin{array}{c}\text { Intensywność } \\
\text { (c/s) }\end{array}$ & \begin{tabular}{|l|} 
Błąd \\
2-sig
\end{tabular} & $\begin{array}{c}\text { Udział atomowy } \\
(\%)\end{array}$ & $\begin{array}{c}\text { Koncentracja } \\
\text { (wt. \%) }\end{array}$ \\
\hline \multirow{5}{*}{1} & Co & 225,91 & 2,639 & 63,718 & 62,190 \\
\hline & $\mathrm{Cr}$ & 157,02 & 2,271 & 31,586 & 27,200 \\
\hline & Mo & 13,04 & 0,679 & 2,532 & 4,024 \\
\hline & W & 5,83 & 0,394 & 2,163 & 6,587 \\
\hline & & & & 100,000 & 100,000 \\
\hline \multirow{5}{*}{2} & Co & 234,71 & 2,694 & 63,324 & 61,418 \\
\hline & $\mathrm{Cr}$ & 158,79 & 2,266 & 30,703 & 26,273 \\
\hline & Mo & 21,64 & 0,873 & 3,983 & 6,290 \\
\hline & $\mathrm{W}$ & 5,61 & 0,423 & 1,989 & 6,019 \\
\hline & & & & 100,000 & 100,000 \\
\hline
\end{tabular}

\section{Badania twardości}

Twardość Vickersa na urządzeniu Instron Wolpert TESTOR 2100 wyznaczono jako średnią z 25 prób (rys.6). W tabeli 4 zamieszczono wyniki badań twardości metodą Vickersa. Przy zbliżonym składzie chemicznym stopu CoCr-Mo z technologii odlewania i spiekania, średnie wartości twardości kształtują się na zróżnicowanym poziomie. W próbkach z technologii odlewania wartość średnia twardości wynosiła $5435,15 \mathrm{MPa}$, a w próbkach z technologii DMLS wynosiła 6662,57 MPa.
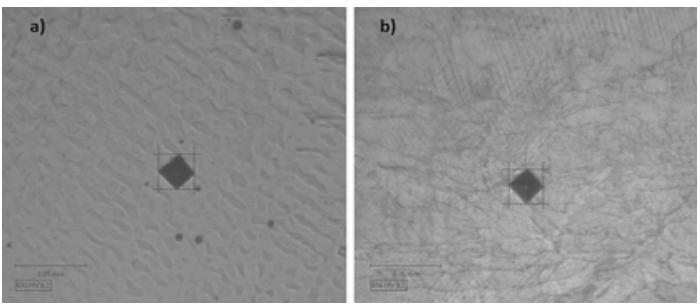

Rys.6. Przykładowe odciski penetratora w próbkach z: a) technologii odlewania, b) technologii DMLS

Tabela 4. Zestawienie wyników pomiarów twardości dla materiałów badanych na Instron Wolpert TESTOR 2100

\begin{tabular}{|c|c|c|}
\hline Badany materiał & $\begin{array}{c}\text { Remanium } \\
\text { GM 800+ }\end{array}$ & $\begin{array}{c}\text { EOS } \\
\text { CobaltChrome } \\
\text { SP2 }\end{array}$ \\
\hline $\begin{array}{c}\text { Wartość średnia twardości H, } \\
{[\mathrm{MPa}]}\end{array}$ & 5435,15 & 6662,57 \\
\hline $\begin{array}{c}\text { Niepewność standardowe typa } \\
\mathrm{A} \mathrm{u}_{(\mathrm{H})},[\mathrm{MPa}]\end{array}$ & 665,07 & 325,35 \\
\hline Wariancja $\mathrm{u}_{(\mathrm{H})}{ }^{2},[\mathrm{MPa}]$ & 442323,15 & 105854 \\
\hline $\begin{array}{c}\text { Niepewność rozszerzona } \mathrm{U}, \\
{[\mathrm{MPa}]}\end{array}$ & 1330,15 & 650,7 \\
\hline
\end{tabular}

\section{Dyskusja}

Stop Co-Cr-Mo znalazł zastosowanie w technice medycznej i dentystycznej już w latach 60. XX wieku. Początkowo stosowany był jako materiał do konstrukcji protez. Wieloletnie próby i badania ujawniły doskonałe własności tego materiału do wykonywania podbudów i uzupełnień protetycznych. Zalety tego stopu to: wysoka wytrzymałość na zginanie, wysoka twardość i odporność na ścieranie, którą zapewnia kobalt, wysoka odporność na korozję, którą zapewniają chrom i molibden oraz biokompatybilność.

W mikrostrukturach odlewanych z Remanium GM 800+ metoda próżniowo-ciśnieniową zaobserwowano obecność dendrytów oraz nieciągłości na ich granicach. W niektórych próbkach ujawniono niejednorodności strukturalne w postaci grubych dendrytów z rzadziznami. Ponadto, w strukturze odlewanej stwierdzono występowanie porowatości.

Mikrostruktura stopu EOS CobaltChrome SP2 z technologii DMLS wykazuje jednorodność składu chemicznego oraz brak porowatości. Na obrazach SEM widoczne są zarysowania granic ziaren, które po przez swoje zróżnicowane geometrycznie kształty zapewniają zwartość mikrostruktury. Problemem mikrostruktury powstałej w wyniku spiekania proszków metali zajmowało się wiele ośrodków, a wyniki badań znalazły potwierdzenie w obserwacjach innych autorów [9-16].

Analiza pierwiastkowa obu technologicznie zróżnicowanych stopów Co-Cr-Mo potwierdziła obecność takich pierwiastków jak: kobalt, chrom, molibden i wolfram. W wytypowanych losowo punktach można stwierdzić, że nie ma znaczących rozrzutów procentowych metali tworzących stopy (Rys.4 i 5, Tab.2 i 3).

Na podstawie przeprowadzonych badań mechanicznych metoda Vickersa można stwierdzić, że stop z Remanium GM 800+ osiąga niższe wartości twardości niż stop EOS CobaltChrome SP2 z technologii DMLS. Biomateriał z odlewania wykazał średnią wartość twardości na poziomie $5435,15 \mathrm{MPa}$, a z technologii spiekania średnią wartość twardości na poziomie ok. $6662,57 \mathrm{MPa}$. Wysoka wartość twardości jest korzystna ze względu na to, że podbudowy protetyczne muszą charakteryzować się odpornością na duże, złożone obciążenia w warunkach żucia $[13,16,17]$. Ponadto wymagana jest stabilność kształtu ze względu na licowanie ceramiką $\mathrm{i}$ zapewnienie szczelności $z$ filarami protetycznymi [18-21]. Na podstawie analizy wyników badań zauważono 2-krotnie wyższą niepewność pomiaru typu A dla próbek stopu Co-Cr-Mo wykonanych w technologii odlewania niż dla próbek wykonanych w technologii spiekania laserowego z selektywnych proszków metali. Zaobserwowane zjawisko świadczy o tym, że w stopie EOS CobaltChrome SP2 nie występują duże różnice twardości w objętości próbki. Może to stanowić wskazanie do wykorzystania technologii DMLS na podbudowy konstrukcji protetycznych. Elementy wykonane $w$ tej technologii mają docelowy kształt i wymiary i nie wymagają etapu dodatkowej obróbki, która może prowadzić do niedokładności w wykonaniu konstrukcji protetycznej.

W technologii odlewania występują duże straty materiału spowodowane koniecznością odcięcia zapełnionych metalem kanałów odlewniczych, a proces topienia i krzepnięcia metali wchodzących w skład stopu wpływa na pogorszenie właściwości mikromechanicznych uzyskanej konstrukcji.

\section{Wnioski}

W badaniach biomateriałów wykonanych ze stopu CoCr-Mo z wykorzystaniem mikroskopii skaningowej stwierdzono mikrostrukturę o układzie dendrytycznym dla stopu Remanium GM 800+ z technologii odlewania oraz 
jednorodną, nie posiadającą porów mikrostrukturę z występującymi obszarami ziaren równoosiowych jak i ziaren o silnie wydłużonym kształcie w próbkach EOS CobaltChrome SP2 z technologii DMLS.

$W$ badaniach mechanicznych można zauważyć różnice twardości dla próbek wykonanych w dwóch różnych technologiach. Stop Co-Cr-Mo z technologii DMLS charakteryzuje się wyższą twardością i mniejszymi różnicami w rozkładzie twardości na całej powierzchni próbki w porównaniu do stopu Co-Cr-Mo z technologii odlewania.

Na podstawie zrealizowanych badań można stwierdzić, że przyrostowe spiekanie laserowe $z$ selektywnych proszków w wyniku czego uzyskuje się podbudowę ze stopu Co-Cr-Mo - w aspekcie mikrostruktury jak i ocenionych parametrów wytrzymałościowych - jest nową technologią preferowaną do wykonawstwa konstrukcji nośnych dla stomatologii. Może ono stanowić alternatywę dla klasycznych metod opartych o tradycyjne odlewnictwo. Technologia ta nie powoduje generowania strat materiału charakterystycznych dla technologii odlewania i jest proekologiczna.

\section{Podziękowania}

Autorzy chcą serdecznie podziękować za wsparcie finansowe $w$ ramach grantu dziekańskiego nr. WIMiR/kkem/44/15.11.130.967/2014.

\section{LITERATURA}

[1] Rodrigues W.C., Broilo L.R., Schaeffer L., Knörnschild G., Espinoza F.R.M., Powder metallurgical processing of Co-28\% Cr-6\% Mo for dental implants: Physical, mechanical and electrochemical properties, Powder Technology, 206 (2011), $\mathrm{nr} .3,233-238$

[2] Takaichi A., Nakamoto T., Joko N., Nomura N., Tsutsumi Y., Migita S., Hanawa T., Microstructures and mechanical properties of Co-29Cr-6Mo alloy fabricated by selective laser melting process for dental applications, Journal of the mechanical behavior of biomedical materials, 21 (2013), 67-76.

[3] Ciocca L., Fantini M., de Crescenzio F., Corinaldesi G., Scotti R., Direct metal laser sintering (DMLS) of a customized titanium mesh for prosthetically guided bone regeneration of atrophic maxillary arches, Medical \& Biological Engineering \& Computing, 49 (2011), nr.11, 1347-52

[4] Iseri U., Ozkurt Z., Kazazoglu E., Shear bond strengths of veneering porcelain to cast, machined and laser-sintered titanium, Dental Materials Journal, 30 (2011), nr.3, 274-80

[5] Ramırez L.E., Castro M., Méndez M., Lacaze J., Herrera M., Lesoult G., Precipitation path of secondary phases during solidification of the Co-25.5\% Cr-5.5\% Mo-0.26\% C alloy, Scripta materialia, 47 (2002), nr.12, 811-816

[6] Jevremovic D., Puskar T., Kosec B., Vukelic D., Budak I., Aleksandrovic S., Williams R., The analysis of the mechanical properties of $\mathrm{F} 75 \mathrm{Co}-\mathrm{Cr}$ alloy for use in selective laser melting (SLM) manufacturing of removable partial dentures (RPD), Metalurgija, 51 (2012), nr.2, 171-174

[7] España F.A., Balla V.K., Bose S., Bandyopadhyay A., Design and fabrication of CoCrMo alloy based novel structures for load bearing implants using laser engineered net shaping, Materials Science and Engineering: C, 30 (2010), nr.1, 50-57

[8] Norma PN-EN ISO 6507-1:2007: Metale - Pomiar twardości sposobem Vickersa - Część 1: Metoda badań

[9] Giacchi J.V., Morando C.N., Fornaro O., Palacio H.A., Microstructural characterization of as-cast biocompatible Co-
Cr-Mo alloys, Materials Characterization, 62 (2011), nr.1, 5361

[10]Ram G.J., Esplin C.K., Stucker B.E., Microstructure and wear properties of LENS $\AA$ deposited medical grade CoCrMo, Journal of Materials Science: Materials in Medicine, 19 (2008), nr.5, 2105-2111

[11] Matković T., Matković P., Malina J., Effects of Ni and Mo on the microstructure and some other properties of $\mathrm{Co}-\mathrm{Cr}$ dental alloys, Journal of Alloys and Compounds, 366 (2004), nr.1, 293-297

[12]Mori M., Yamanaka K., Matsumoto H., Chiba A., Evolution of cold-rolled microstructures of biomedical Co-Cr-Mo alloys with and without $\mathrm{N}$ doping, Materials Science and Engineering: A, 528 (2010), nr.2, 614-621

[13] Yoda K., Takaichi A., Nomura N., Tsutsumi Y., Doi H., Kurosu S., Hanawa T., Effects of chromium and nitrogen content on the microstructures and mechanical properties of as-cast $\mathrm{Co}-$ Cr-Mo alloys for dental applications, Acta biomaterialia, 8 (2012), nr.7, 2856-2862

[14]Karaali A., Mirouh K., Hamamda S., Guiraldenq P., Microstructural study of tungsten influence on $\mathrm{Co}-\mathrm{Cr}$ alloys, Materials Science and Engineering: A, 390 (2005), nr.1, 255-259

[15] Sato Y., Nomura N., Fujinuma S., Chiba A., Microstructure and tensile properties of hot-pressed co-cr-mo alloy compacts for biomedical applications, Journal of the Japan Institute of Metals, 72 (2008), nr.7, 532-537

[16] Sato Y., Nomura N., Fujinuma S., Chiba A., Microstructure and mechanical properties of hot-pressed co-cr-mo alloy compacts, Advanced Materials Research, 26 (2007), 769-772

[17] Gradzka-Dahlke M., Dabrowski J.R., Dabrowski B., Modification of mechanical properties of sintered implant materials on the base of Co-Cr-Mo alloy, Journal of materials processing technology, 204 (2008), nr.1, 199-205

[18] Henriques B., Soares D., Silva F.S., Microstructure, hardness, corrosion resistance and porcelain shear bond strength comparison between cast and hot pressed CoCrMo alloy for metal-ceramic dental restorations, Journal of the mechanical behavior of biomedical materials, 12 (2012), 83-92

[19] Wu L., Zhu H., Gai X., Wang Y., Evaluation of the mechanical properties and porcelain bond strength of cobalt-chromium dental alloy fabricated by selective laser melting, The Journal of prosthetic dentistry, 111 (2014), nr.1, 51-55

[20]Quante K., Ludwig K., Kern M., Marginal and internal fit of metal-ceramic crowns fabricated with a new laser melting technology, Dental Materials, 24 (2008), nr.10, 1311-1315

[21] Hanawa T., Hiromoto S., Asami K., Characterization of the surface oxide film of a Co-Cr-Mo alloy after being located in quasi-biological environments using XPS, Applied Surface Science, 183 (2001), nr.1, 68-75

Autorzy: mgr inż. Łukasz Bojko, Akademia Górniczo-Hutnicza, Wydział Inżynierii Mechanicznej i Robotyki, Katedra Konstrukcji i Eksploatacji Maszyn, al. Mickiewicza 30, 30-059 Kraków, E-mail: Ibojko@agh.edu.pl; dr hab. inż. Anna M. Ryniewicz, prof. AGH, Akademia Górniczo-Hutnicza, Wydział Inżynierii Mechanicznej $i$ Robotyki, Katedra Konstrukcji i Eksploatacji Maszyn, al. Mickiewicza 30, 30-059 Kraków, E-mail: anna@ryniewicz.pl; dr inż. Rafał Bogucki, Politechnika Krakowska, Wydział Mechaniczny, Instytut Inżynierii Materiałowej, Zakład Materiałów Inżynierskich, al. Jana Pawła II 37, 31-864 Kraków, E-mail: rbogucki@mech.pk.edu.pl; dr inż. Paweł Pałka, Akademia Górniczo-Hutnicza, Wydział Metali Nieżelaznych, Katedra Nauki o Materiałach i Inżynierii Metali Nieżelaznych, al. Mickiewicza 30, 30059 Kraków, E-mail: pawel.palka@agh.edu.pl. 